\title{
Poly(A) site choice and Pol2 CTD Serine-5 status govern IncRNA control of phosphate-responsive tgp1 gene expression in fission yeast
}

\author{
ANA M. SANCHEZ, ${ }^{1}$ STEWART SHUMAN, ${ }^{2}$ and BEATE SCHWER ${ }^{1}$ \\ ${ }^{1}$ Department of Microbiology and Immunology, Weill Cornell Medical College, New York, New York 10065, USA \\ ${ }^{2}$ Molecular Biology Program, Sloan-Kettering Institute, New York, New York 10065, USA
}

\begin{abstract}
Expression of fission yeast glycerophosphate transporter Tgp1 is repressed in phosphate-rich medium and induced during phosphate starvation. Repression is enforced by transcription of the nc-tgp1 locus upstream of tgp1 to produce a long noncoding (Inc) RNA. Here we identify two essential elements of the nc-tgp1 promoter: a TATA box ${ }^{-30}$ TATATATA $^{-23}$ and a HomolD box ${ }^{-64}$ CAGTCACA $^{-57}$, mutations of which inactivate the nc-tgp1 promoter and de-repress the downstream tgp1 promoter under phosphate-replete conditions. The nc-tgp1 IncRNA poly(A) site maps to nucleotide +1636 of the transcription unit, which coincides with the binding site for Pho7 $\left({ }^{1632}\right.$ TCGGACATTCAA $\left.{ }^{1643}\right)$, the transcription factor that drives tgp1 expression. Overlap between the IncRNA template and the tgp1 promoter points to transcriptional interference as the simplest basis for IncRNA repression. We identify a shorter RNA derived from the nc-tgp1 locus, polyadenylated at position +508 , well upstream of the tgp1 promoter. Mutating the nc-tgp1-short RNA polyadenylation signal abolishes de-repression of the downstream tgp1 promoter elicited by Pol2 CTD Ser5Ala phospho-site mutation. Ser5 mutation favors utilization of the short RNA poly(A) site, thereby diminishing transcription of the IncRNA that interferes with the tgp1 promoter. Mutating the nctgp1-short RNA polyadenylation signal attenuates induction of the tgp1 promoter during phosphate starvation. Polyadenylation site choice governed by CTD Ser5 status adds a new level of IncRNA control of gene expression and reveals a new feature of the fission yeast CTD code.
\end{abstract}

Keywords: phosphate homeostasis; polyadenylation; CTD code

\section{INTRODUCTION}

Phosphate homeostasis in the fission yeast Schizosaccharomyces pombe is achieved by an intricate network of positive and negative influences on the transcription of genes encoding three proteins involved in extracellular phosphate mobilization and uptake: a cell surface acid phosphatase Pho1, an inorganic phosphate transporter Pho84, and a glycerophosphate transporter Tgp1 (Carter-O'Connell et al. 2012). These genes are repressed during growth in phosphate-rich medium and induced during phosphate starvation. Induction of the phosphate-regulated genes is dependent on transcription factor Pho7 (Henry et al. 2011; Carter-O'Connell et al. 2012). Repression of pho1 under phosphate-replete conditions is itself an active process involving protein kinases Csk1 and Cdk9, and the phosphorylation of the carboxyl-terminal domain (CTD) of the Rpb1 subunit of RNA polymerase II

Corresponding authors: s-shuman@ski.mskcc.org, bschwer@med. cornell.edu

Article is online at http://www.rnajournal.org/cgi/doi/10.1261/rna. 063966.117.
(Pol2) (Carter-O'Connell et al. 2012; Schwer et al. 2014, 2015; Chatterjee et al. 2016).

Recent studies have unveiled a role for long noncoding (lnc) RNAs in phosphate-regulated expression of the pho1 and tgpl genes. The prt lncRNA, initiating 1147 nucleotides (nt) upstream of the pho1 mRNA transcription start site, represses pho1 in cis during phosphate-replete growth (Lee et al. 2013; Shah et al. 2014; Schwer et al. 2015; Chatterjee et al. 2016). phol expression from the prt-phol locus is inversely correlated with the activity of the prt promoter, which resides in a 110-nt DNA segment preceding the prt transcription start site. Within the prt promoter, there are two elements that dictate its strength: (i) a TATA box $\left({ }^{-37}\right.$ TATATATA $\left.^{-30}\right)$ that is essential for prt transcription; and (ii) an upstream segment from -110 to -62 that augments prt transcription (Chatterjee et al. 2016). The

(C) 2018 Sanchez et al. This article is distributed exclusively by the RNA Society for the first 12 months after the full-issue publication date (see http://rnajournal.cshlp.org/site/misc/terms.xhtml). After 12 months, it is available under a Creative Commons License (Attribution-NonCommercial 4.0 International), as described at http://creativecommons.org/licenses/by$\mathrm{nc} / 4.0 /$. 
positive contributions of the upstream segment stem, at least in part, from the presence of a HomolD sequence $\left({ }^{-75}\right.$ CAGTCACG $\left.^{-68}\right)$. Manipulations of the prt promoter in the context of the prt-pho1 locus that either delete the upstream DNA segment or mutate the TATA box cause de-repression of phol in phosphate-replete cells. Unlike pho1, expression of prt is independent of Pho7 (Schwer et al. 2015). The phol promoter resides within a 283-nt DNA segment upstream of the mRNA start site and its activity depends on two tandem dodecamer sequences [consensus motif $\left.5^{\prime}-\mathrm{TCG}(\mathrm{G} / \mathrm{C})(\mathrm{A} / \mathrm{T}) \mathrm{xxTTxAA}\right]$ that are binding sites for the Pho7 transcription factor (Chatterjee et al. 2016; Schwer et al. 2017).
In the case of $\operatorname{tgp} 1$, the lncRNA $n c$ - $\lg p 1$, initiating $1865 \mathrm{nt}$ upstream of the tgp1 AUG start codon (Fig. 1A), represses tgp1 in cis during phosphate-replete growth (Ard et al. 2014). $\operatorname{tg} p 1$ is de-repressed when the $n c$-tgpl locus is disrupted either by deleting the $n c$ - $\operatorname{tg} p 1$ transcription start site and upstream flanking DNA (embracing the putative $n c$ - $\operatorname{sg} 1$ promoter) or by inserting a $\mathrm{ura}^{+}$cassette (in reverse orientation) into the $5^{\prime}$ end of the $n c$-tgp 1 transcription unit (Ard et al. 2014). The cis and trans factors that control nc-tgp1 transcription are presently unknown. However, it is clear that prt and $n c$-tgp 1 lncRNA levels are restrained by the action of the nuclear exosome; they increase sharply when the Rrp6 nuclear exosome subunit is absent. The turnover of these
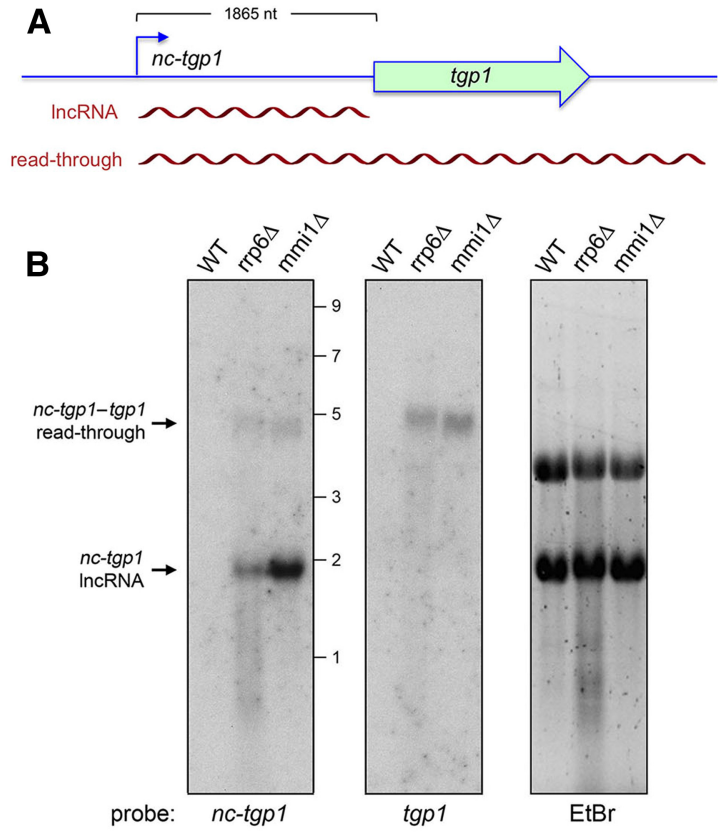

C

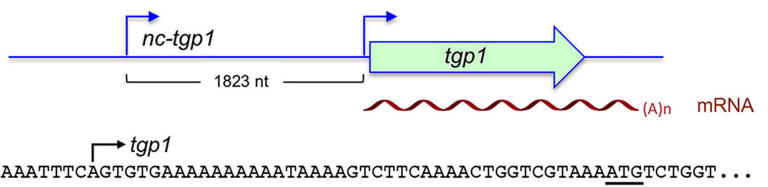

...TGAATATTAGTTGCTTAATGTGTTTACTGTTAAATAATTGAAAAATTATAATATCaaaaaaaaaaa $\operatorname{poly}(A)$ tail

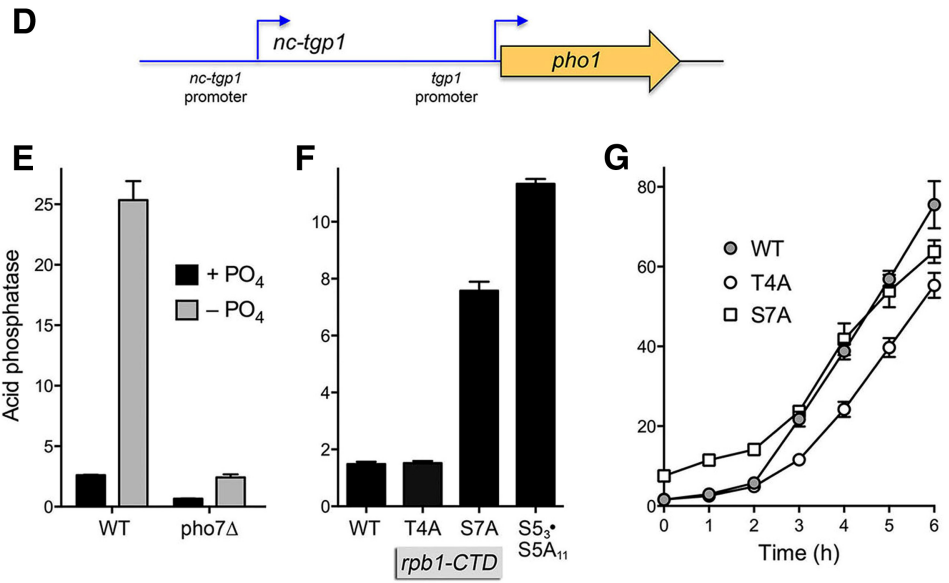

FIGURE 1. Transcripts derived from the $n c$-tgp 1 and $\operatorname{tg} p 1$ loci and plasmid reporter for dissection of $n c$-tgpl control of tgp1 expression. $(A)$ The tandem $n c$-tgp1-tgp 1 locus is shown with the $n c$-tgp 1 transcription start site indicated by the blue arrow and the tgp 1 ORF depicted as a green bar with arrowhead indicating the direction of transcription. The distance between the $n c$-tgp 1 transcription initiation site and the ATG translation start site of the tgp 1 ORF is indicated by the bracket. The two nc-tgp 1 transcripts detected by northern analysis (in panel $B$ ) are depicted as wavy lines below the DNA. (B) Northern blotting. Total RNA from wild-type (WT), rrp6 6 , and mmils cells was resolved by agarose gel electrophoresis, and ethidium bromide-stained ribosomal RNAs (EtBr, right panel) were visualized prior to transfer of the gel contents to membrane, which was hybridized to ${ }^{32} \mathrm{P}$-labeled $n c$-tgp1 (left panel) and tgp1 (middle panel) DNA probes. The positions and sizes (kb) of RNA size markers are indicated on the left panel. $(C) \operatorname{tgp} 1$ mRNA. The $n c$-tgp1-tgp1 locus is shown with the distance between the $n c$-tgp 1 and $\operatorname{tgp} 1$ transcription initiation sites indicated by the bracket. The DNA sequence surrounding the tgp 1 transcription start site (mapped by primer extension and indicated by the black arrow) is shown on the top line; the tgp1 ATG translation start codon is underlined. The cDNA sequence including and preceding the poly(A) tail of the tgp1 mRNA is shown on the bottom line; the consensus poly(A) signal is highlighted in white on black background. $(D)$ The plasmid-borne $n c$ $\operatorname{tgp} 1$-tgp $1 \cdot$ phol reporter cassette is shown with the mapped transcription start sites of the $n c$-tgp 1 lncRNA and tgp 1 mRNA indicated by arrows. The pho1 ORF is depicted as a gold bar with arrowhead. (E) The $n c$-tgp1-tgpl $\bullet$ pho1 plasmid was introduced into pho1 $\Delta$ yeast cells that were either $p h o 7^{+}$ (WT) or pho7 $\Delta$. Cells grown for $3 \mathrm{~h}$ in synthetic medium containing $15.5 \mathrm{mM}$ phosphate $\left(+\mathrm{PO}_{4}\right)$ or in medium lacking exogenous phosphate $\left(-\mathrm{PO}_{4}\right)$ to elicit the starvation response were assayed for acid phosphatase activity by conversion of $p$-nitrophenylphosphate to $p$-nitrophenol. The $y$-axis specifies the phosphatase activity $\left(A_{410}\right)$ normalized to input cells $\left(A_{600}\right)$. The error bars denote SEM. $(F)$ CTD mutations de-repress regulated tgp1 expression during phosphate-replete growth. The nc-tgp1-tgpl-pho1 reporter plasmid was introduced into pho1 $\Delta$ cells in which the rpb1 chromosomal locus was replaced by alleles rpb1-CTD-WT, CTD-T4A, CTD-S7A, or CTD-S5 $S 5 A_{11}$. Cells grown in phosphate-replete medium were assayed for acid phosphatase activity. $(G)$ Time course of the phosphate starvation response. The indicated CTD strains bearing the $n c$ $\operatorname{tgp} 1-\operatorname{tgp} 1 \cdot$ phol reporter plasmid were assayed for acid phosphatase activity immediately prior to and at hourly intervals after transfer to medium lacking exogenous phosphate. 
lncRNAs by the exosome is aided by Mmil (Ard et al. 2014; Shah et al. 2014), a YTH domain-containing protein that recognizes determinants of select removal (DSR) in the target RNA (Harigaya et al. 2006; Yamashita et al. 2012; Chatterjee et al. 2016; Wang et al. 2016).

Whereas there are divergent views on the role of heterochromatin in the IncRNA-mediated repression of fission yeast phosphate-responsive genes, the simplest model is that transcription of the upstream lncRNA in cis is what interferes with expression of the downstream genes encoding Pho1 or Tgp1 in phosphate-replete cells, likely by displacing the Pho7 transcription factor from the pho1 and tgp1 promoter DNAs (Ard et al. 2014; Chatterjee et al. 2016). By extension, the simplest view of the response to phosphate starvation is that it causes cessation of lncRNA transcription across the downstream gene promoter (in a manner as yet uncharted) and alleviates the downstream interference.

We are interested in elucidating the signals that affect this dynamic during phosphate starvation and in the role of the Pol2 CTD in establishing or overriding the repressed state imposed by lncRNA synthesis. Here we focus on the repression of $\operatorname{tg} p 1$ by $n c$-tgp 1 . We address the following questions: (i) What comprises the $n c$-tgp 1 promoter? (ii) Does $n c$-tgp 1 promoter strength correlate with tgp1 repression? (iii) How do CTD phospho-site mutations affect $n c$-tgp 1 and tgp 1 expression? (iv) Does mutating DSR-like elements in the $n c$ tgp 1 RNA affect tgp 1 phosphate-responsiveness? (v) Is there a connection between $n c$-tgp 1 lncRNA $3^{\prime}$ end formation and $\operatorname{tg} p 1$ promoter activity?

In the course of answering these questions, we identified a novel short polyadenylated RNA derived from the $n c$-tgp 1 transcription unit and found that mutation of its polyadenylation signal abolished the de-repression of the downstream tgp 1 promoter elicited by CTD Ser5Ala phospho-site mutation. Ser5Ala promotes utilization of the short RNA poly(A) site located upstream of the tgp 1 promoter, thereby diminishing transcription of the lncRNA that overlaps and interferes with the $\operatorname{tg} p 1$ promoter. We find that mutating the $n c$-tgp 1 short RNA polyadenylation signal attenuates induction of the tgp 1 promoter during phosphate starvation. Polyadenylation site choice responsive to Pol2 CTD status comprises a new means of lncRNA control of gene expression.

\section{RESULTS}

\section{Two transcripts derived from the nc-tgp1 locus}

Northern analysis of total RNA from phosphate-replete wildtype $S$. pombe cells using $n c$-tgp 1 and $\operatorname{tg} p 1$ probes failed to detect transcripts from either locus. In contrast, in a mmil $\Delta$ strain, bearing a mei4 mutation that suppresses the lethality of mmi1s (Sugiyama and Sugioka-Sugiyama 2011), we detected two discrete transcripts that hybridized to the $n c$-tgp 1 probe: a $\sim 1.9 \mathrm{~kb}$ RNA corresponding to the $n c$-tgp 1 lncRNA; and a $\sim 4.6 \mathrm{~kb}$ RNA that extended through the tgp1 gene and was therefore recognized by the tgp1-specific probe (Fig. 1A,B). The $n c$-tgpl $\operatorname{lncRNA}$ and the $n c$-tgpltgp1 read-through transcript were also detectable by northern analysis of RNA from $r r p 6 \Delta$ cells (Fig. 1B). A transcript corresponding to the $\sim 2.5 \mathrm{~kb}$ tgp 1 mRNA (Ard et al. 2014) was not detected in phosphate-replete mmils or rrp6 $\Delta$ cells, affirming that tgp 1 is tightly repressed during growth in phosphate-rich medium (more so than pho1, which is expressed at a basal level in phosphate-replete cells).

\section{tgp1 mRNA initiation and polyadenylation sites}

Reverse transcriptase primer extension analysis located the $5^{\prime}$ end of the tgp $1 \mathrm{mRNA}$ to a single site $42 \mathrm{nt}$ upstream of the start codon of the tgp 1 open reading frame (Fig. 1C; Schwer et al. 2017). Thus, the tgp1 mRNA transcription start site is $1823 \mathrm{nt}$ downstream from the $n c$-tgp 1 lncRNA initiation site (Fig. 1C). Here we mapped the site of polyadenylation of the tgp 1 mRNA by $3^{\prime}$ RACE using as template total RNA isolated from phosphate-starved wild-type cells. Sequencing of 14 individual cDNA clones revealed that $43 \%(6 / 14)$ had the identical junction to a poly(A) tail at a site $2102 \mathrm{nt}$ downstream from the tgp1 transcription start site (Fig. 1C). The dominant tgp 1 poly(A) site is located 19 nt downstream from a fission yeast AAAUAA polyadenylation signal (Fig. 1C; Mata 2013). Seven additional poly(A) junctions, six recovered once and one recovered twice among the 14 cDNA clones, were distributed within a 277-nt segment (Supplemental Fig. S1). The most proximal poly(A) site was located $1940 \mathrm{nt}$ downstream from the transcription start site, and the most distal poly(A) site was situated $2216 \mathrm{nt}$ from the transcription start site. The most distal poly(A) site is preceded by two tandem fission yeast AAUAAA polyadenylation signals (Supplemental Fig. S1; Mata 2013).

We also performed 3' RACE analysis using RNA isolated from phosphate-replete mmil $\Delta$ cells that express the $n c$ tgp1-tgp1 read-through transcript. Of 13 individual cDNA clones sequenced, four had a poly(A) tail at the position corresponding to the dominant poly(A) site of the tgp $1 \mathrm{mRNA}$ (Supplemental Fig. S2). Four of the cDNA clones had a poly(A) tail at the position corresponding to the most distal poly(A) site of the tgp 1 mRNA (Supplemental Fig. S2). The majority of the poly(A) sites of the nc-tgp1-tgp1 readthrough transcript (9/13) were downstream from fission yeast polyadenylation signals. Five other poly(A) junctions were each recovered once (Supplemental Fig. S2), two of which were identical to "singlet" poly(A) sites detected by 3' RACE of the tgp 1 mRNA.

The tgp 1 gene is annotated in Pombase (www.pombase. org) as containing a putative 46-nt intron interrupting the $3^{\prime}$ end of a predicted open reading frame that, assuming the intron is spliced out in the mature $\operatorname{tg} p 1 \mathrm{mRNA}$, would encode a predicted polypeptide of 543 amino acids. Our $3^{\prime}$ RACE analysis of the tgp 1 mRNA from phosphate-starved fission yeast, which used sense strand primers 
corresponding to sequences $5^{\prime}$ of the predicted intron, yielded polyadenylated cDNA clones that, in every case (14/14), contained the 46-nt segment thought to comprise an intron (Supplemental Fig. S1). We conclude that this element is not a bona fide intron and is not spliced out during phosphate starvation, the only time when $\operatorname{tgp} 1 \mathrm{mRNA}$ is known to be transcribed. (The 46-nt segment is also retained in all of the 13 cDNA clones obtained by $3^{\prime}$ RACE of the nc-tgp1tgp1 read-through transcript in phosphate-replete mmils cells [Supplemental Fig. S2].) The corrected 1584-nt open reading frame in the tgp 1 mRNA encodes a 528-aa protein (Supplemental Fig. S1) that contains a C-terminal Lys528 instead of a C-terminal 16-aa peptide that would have been encoded had the intron been spliced.

\section{Plasmid-based reporter assay to study regulated expression of $\operatorname{tgp} 1$}

Whereas the regulation of phol expression is conveniently studied by measuring acid phosphatase enzyme activity on the surface of live yeast cells, analyses of tgpl expression have relied on steady-state tgp1 RNA levels. Because our goal here was to dissect what drives $n c$-tgp 1 lncRNA expression and its influence on $\operatorname{tgp} 1$ transcription, we developed a plasmid-based reporter system inspired by the recently described prt-pho1 plasmid reporter, which recapitulated the features of regulated phol expression that had been determined for the chromosomal prt-phol locus (Chatterjee et al. 2016). As depicted in Figure 1D, we isolated a fragment of the $n c$-tgp1-tgp1 locus, spanning $301 \mathrm{nt}$ upstream of the $n c$ - $\operatorname{tg} p 1$ transcription initiation site (encompassing the putative $n c-\operatorname{tgp} 1$ promoter) and the entire $1865 \mathrm{nt}$ segment between the $n c$-tgp1 transcription start site and the tgp1 translation start codon (containing the putative tgp1 promoter), and fused it to the phol ORF and its native $3^{\prime}$ flanking DNA. We cloned the $n c$-tgp1-tgp $1 \cdot p h o 1$ reporter cassette into a fission yeast plasmid, which we then introduced into a pho1s strain in which the chromosomal phol gene had been deleted. Plasmid-bearing pho1s cells grown to mid-log phase in liquid culture in phosphate-replete YES medium were washed and then incubated for 3 $\mathrm{h}$ in synthetic medium containing $15.5 \mathrm{mM}$ phosphate $\left(+\mathrm{PO}_{4}\right)$ or in medium lacking exogenous phosphate $\left(-\mathrm{PO}_{4}\right)$ to elicit the starvation response. Acid phosphatase activity was quantified by incubating suspensions of serial dilutions of the cells for $5 \mathrm{~min}$ with $p$-nitrophenylphosphate and assaying colorimetrically the formation of $p$-nitrophenol. Product formation in the linear response range, normalized to cell density, is plotted on the $y$-axis in Figure $1 \mathrm{E}$. The low basal phosphatase activity of $n c-\operatorname{tg} p 1-\operatorname{tg} p 1 \cdot p h o 1$ cells in phosphate-replete medium was increased 10-fold after $3 \mathrm{~h}$ of phosphate starvation. Moreover, the basal activity and the starvation response of the $n c-\operatorname{tg} p 1-\operatorname{tg} p 1 \cdot p h o 1$ reporter was attenuated in a pho7s strain that lacks the Pho7 transcription factor. Thus, the plasmid-borne DNA element containing the $n c-\operatorname{tg} p 1$ gene and the $\operatorname{tg} p 1$ transcription start site suffices to confer phosphate-regulated expression of the acid phosphatase reporter.

\section{Effect of CTD phospho-site mutations on regulated tgp1 expression}

Previous studies had shown that repression of pho1 expression from the prt-pho1 locus (in either chromosomal or plasmid contexts) in phosphate-replete cells is affected by Pol2 CTD phosphorylation status, as gauged by the impact of CTD mutations that eliminate particular phosphorylation marks (Schwer et al. 2014, 2015; Chatterjee et al. 2016). For example, inability to place a Ser7- $\mathrm{PO}_{4}$ mark in $S 7 \mathrm{~A}$ cells de-repressed pho1. Limiting the number of serine-5 CTD sites to three consecutive Ser5-containing CTD heptads also de-repressed pho1. In contrast, inability to place a Thr4- $\mathrm{PO}_{4}$ mark in T4A cells hyper-repressed pho1 under phosphate-replete conditions. Here, to test the impact of these CTD mutations on regulated $\operatorname{tg} p 1$ expression, we introduced the $n c$-tgp1-tgp1 $\bullet$ pho1 reporter plasmid into pho1s cells in which the $r p b 1$ chromosomal locus was replaced by alleles rpb1-CTD-WT, -CTD-T4A, -CTD-S7A, or -CTD$S 5_{3} \cdot S 5 A_{11}$ (Schwer and Shuman 2011; Schwer et al. 2012). Whereas the $T 4 A$ allele had no effect on $n c$-tgp1-tgp1 pho1 reporter activity in phosphate-replete cells, the $S 7 A$ and $S 5_{3} \cdot S 5 A_{11}$ CTD variants elicited fivefold and eightfold increases in activity compared to the wild-type CTD (Fig. 1F).

The time dependence of the phosphate starvation response of the $n c-\operatorname{tg} p 1-\operatorname{tg} p 1 \cdot p h o 1$ reporter in the $r p b 1-C T D-W T$, -CTD-T4A, and -CTD-S7A strains was monitored by scoring acid phosphatase activity immediately prior to and at hourly intervals after transfer of the cells to medium lacking exogenous phosphate (Fig. 1G). The onset of acid phosphatase accumulation in $T 4 A$ cells occurred with a slight delay $(\leq 1 \mathrm{~h})$ compared to $r p b 1-C T D-W T$, though the slope of the increase was similar in both strains. Whereas the $S 7 A$ strain started with a higher basal level of acid phosphatase prior to phosphate starvation, the time course of induction of the $n c$ $\operatorname{tgp} 1-\operatorname{tgp} 1 \cdot p h o 1$ reporter was similar to that of $T 4 A$ cells.

\section{nc-tgp1 transcription: What comprises a nc-tgp1 promoter?}

To address this question, we constructed a plasmid reporter in which the pho1 ORF was fused immediately downstream from a genomic DNA segment containing nucleotides -301 to +6 of the $n c$-tgp 1 transcription unit (Fig. 2A). Because this plasmid generated vigorous acid phosphatase activity when introduced into a pho1s strain (Fig. 2B), we surmised that the 301-nt segment embraces a $n c$-tgp1 promoter and potential regulatory elements. Absence of the Pho7 transcription factor had no effect on the activity of the $n c$ $\operatorname{tgp} 1 \cdot$ pho1 reporter (Fig. 2C). To demarcate cis-acting elements, we serially truncated the $5^{\prime}$ flanking DNA to positions 
A

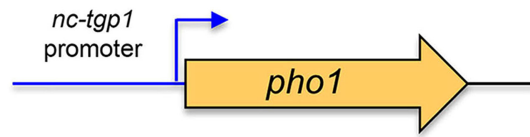
$\underset{-30}{\mathrm{CT}}$
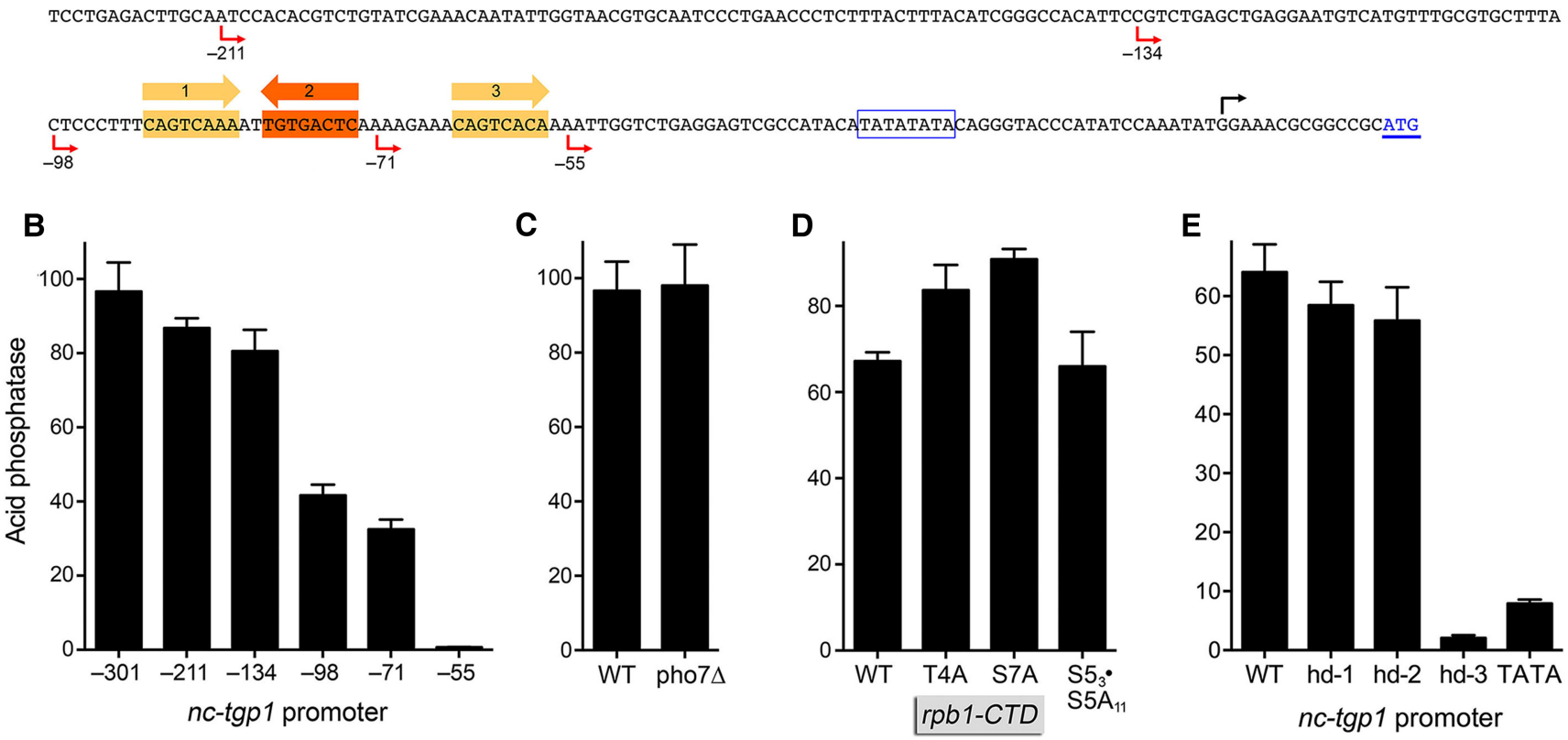

$\mathbf{F}$
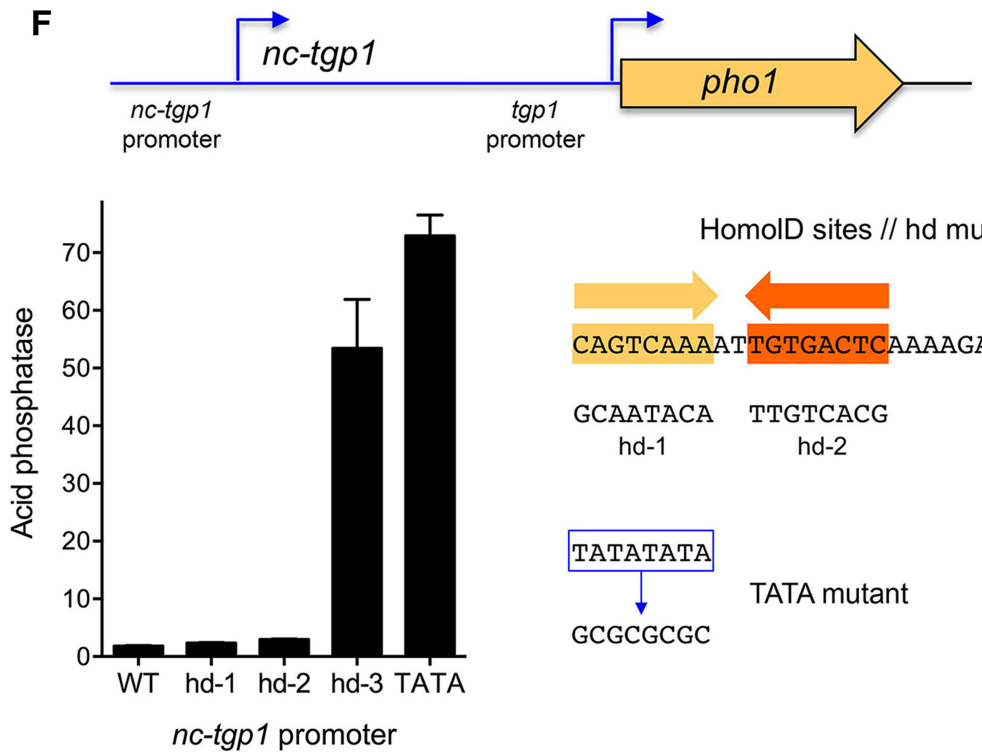

HomolD sites // hd mutants
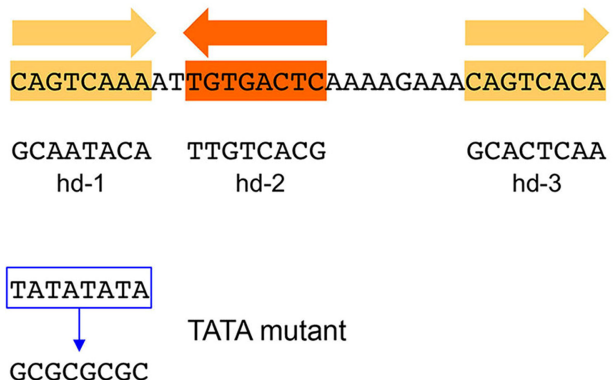

FIGURE 2. HomolD and TATA boxes are essential for $n c$-tgp1 promoter activity and regulation of tgp1. (A) Plasmid reporter of $n c$-tgp 1 promoter activity. The phol ORF (beginning at the underlined ATG translation initiation codon in blue font) was fused downstream from a fragment of genomic DNA containing the $n c$-tgp 1 transcription start site (indicated by the black arrow above the DNA sequence) and $301 \mathrm{nt}$ of $5^{\prime}$ flanking $n c$-tgp1 DNA (presumed to include the $n c$-tgp 1 promoter). Serial truncations of the upstream margin of the $5^{\prime}$ flanking $n c$-tgp 1 DNA were made at positions -211, $-134,-98,-71$, and -55 (indicated by red arrows below the DNA sequence) relative to the $n c$-tgp 1 transcription start site. A putative TATA element is outlined by a blue box. Three putative HomolD elements are shaded in gold (forward orientation) or orange (reverse orientation). (B) Acid phosphatase activity of pho1 $\Delta$ cells bearing the indicated $n c$-tgp 1 promoter-driven phol reporter plasmids. $(C)$ Acid phosphatase activity of phol $\Delta$

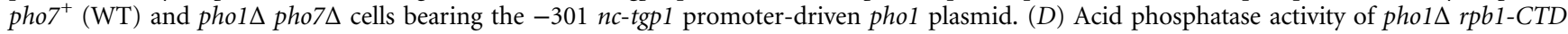
strains bearing the $-301 n c$-tgp 1-pho1 plasmid. (E,F) The indicated mutated versions of individual HomolD sites (hd-1, hd-2, and hd-3) and the TATA box of the $n c$-tgp 1 promoter (shown at right in panel $F$ ) were introduced into the $-301 n c$-tgpl 1 phol reporter and phosphate-replete pho1 $\Delta$ cells bearing the indicated $n c$-tgpl 1 phol reporter plasmids were assayed for acid phosphatase activity (panel $E$ ). $(F)$ The HomolD and the TATA box mutations of the $n c$-tgpl promoter were introduced into the nc-tgpl-tgpl-phol reporter plasmid (shown at the top of the panel). Phosphate-replete pho1s cells bearing the indicated reporter plasmids were assayed for acid phosphatase activity. 
$-211,-134,-98,-71$, and -55 upstream of the $n c$-tgp 1 transcription start site. The acid phosphatase activity of the plasmid-bearing pho1 $\Delta$ cells (Fig. 2B) indicated that the $5^{\prime}$ flanking 134-nt segment sufficed for $n c$-tgp1 promoter-driven expression. Truncation to -98 and -71 reduced acid phosphatase activity to $52 \%$ and $40 \%$ of that driven by the -134 promoter; further truncation to -55 effaced acid phosphatase activity (Fig. 2B). To query whether CTD mutations influence $n c$-tgp 1 promoter-driven transcription, we introduced the $-301 n c$-tgp $1 \cdot p h o 1$ reporter plasmid into the pho1s rpb1-CTD-WT, -CTD-T4A, -CTD-S7A, and -CTD$S 5_{3} \cdot S 5 A_{11}$ strains and measured acid phosphatase expression (Fig. 2D). $n c$-tgp 1 promoted phol activity was identical in the $W T$ and $S 5_{3} \cdot S 5 A_{11}$ strains, from which we conclude that the de-repression of the $n c$ - $\operatorname{tg} p 1-\operatorname{tg} p 1 \cdot p h o 1$ reporter in $S 5_{3} \cdot S 5 A_{11}$ cells was not caused by a decrease in transcription from the $n c$-tgp 1 lncRNA promoter. The $n c$-tgp $1 \cdot p h o 1$ reporter activity in T4A and S7A cells was $25 \%$ and $35 \%$ higher than that in $W T$ cells, respectively (Fig. 2D).

\section{HomolD and TATA boxes are essential for nc-tgp1 promoter activity}

The sequence of the 301-nt DNA segment flanking the $n c$ tgp1 start site is shown in Figure 2A. The promoter deletion analysis suggested the presence of an essential transcriptional element in the interval between -56 and -71 and a stimulatory element located between -72 and -134 . Our inspection of these segments disclosed three sequences that are potential HomolD-box elements (shaded yellow and orange in Fig. 2A). The consensus HomolD element 5'-CAGTCAC(A/G) functions as a Pol2 promoter signal in fission yeast, especially in genes encoding ribosomal proteins (Witt et al. 1993, 1995; Gross and Käufer 1998). The HomolD sequence is a binding site for the essential fission yeast transcription factor Rrn7 (Rojas et al. 2011). The putative HomolD box closest to the $n c$-tgp 1 transcription start site $\left({ }^{-64} \mathrm{CAGTCACA}^{-57}\right.$; box 3 in Fig. 2A) is a perfect match to the HomolD consensus sequence. The candidate HomolD element furthest from the start site $\left({ }^{-90}\right.$ CAGTCAAA $^{-83}$; box 1 in Fig. 2A) deviates by one nucleobase from the consensus sequence. Putative box $2\left({ }^{-80}\right.$ TGTGACTC $\left.^{-73}\right)$, situated between boxes 1 and 3 in the opposite orientation, is a single-base variant GAGTCA CA of the HomolD consensus (Fig. 2A). Our previous studies of the prt-pho1 locus implicated a HomolD box as a driver of prt lncRNA transcription and its ensuing repression of pho1 during phosphate-replete growth (Chatterjee et al. 2016).

Here, to evaluate whether any of the HomolD boxes play a role in lncRNA regulated tgpl expression, we introduced into the $n c$-tgp1-tgp $1 \cdot p h o 1$ reporter multiple nucleotide changes, at six out of eight positions in box 1 , or at seven out of eight positions in boxes 2 or 3 (Fig. 2F). pho1s cells transformed with the mutated $n c$-tgp1-tgp $1 \cdot p h o 1$ reporters hd-1, hd-2, and hd-3 were grown in phosphate-replete medium and tested for acid phosphatase activity in parallel with cells bearing the WT nc-tgp1-tgp1 $\bullet$ phol plasmid. Whereas mutations hd-1 and hd-2 had no effect on the phosphate-repressive state of the $n c-\operatorname{tg} p 1-\operatorname{tg} p 1 \cdot p h o 1$ locus, the hd-3 mutation elicited a de-repression of reporter activity, to a level 29-fold higher than the WT control (Fig. 2F). To judge whether this apparent loss of phosphate regulation was caused by a change in the activity of the $n c-\operatorname{tg} p 1$ promoter, we introduced the hd-1, hd2 , and hd-3 mutations into the $n c$ - $\operatorname{tg} p 1 \cdot p h o 1$ reporter plasmid (Fig. 2E). The salient findings were that whereas hd-1 and hd2 mutations had no significant effect, $n c$-tgp 1 promoter activity was lowered 30-fold by the hd-3 mutation (Fig. 2E). We conclude that HomolD box 3 is an essential component of the $n c$-tgp 1 promoter and that down-regulation of $n c$-tgp 1 promoter-driven lncRNA transcription by its mutation leads to increased activity of the downstream tgpl promoter in phosphate-replete cells.

The $n c$-tgp1 promoter also contains a TATA box sequence ${ }^{-30}$ TATATATA $^{-23}$. To query the role of the TATA element in $n c-\operatorname{tgp} 1$ function, we introduced a TATA mutant (GCGCGC GC) into the $n c$-tgp1-tgp1 1 phol reporter and found that it (akin to the hd-3 mutant) resulted in a 40-fold increase in acid phosphatase activity under phosphate-replete conditions (Fig. 2F) that correlated with an eightfold decrement in the activity of the $n c$ - $\operatorname{tgp} 1$ promoter (Fig. 2E). Thus, the TATA box, too, is a key determinant of $n c$-tgpl promoter function and phosphate repression of the flanking $\operatorname{tg} p 1$ promoter.

\section{Effect of CTD mutations on tgp1 promoter activity}

To interrogate the tgp 1 promoter, we constructed a plasmid reporter in which a genomic DNA segment containing nucleotides -871 to +42 of the $\operatorname{tg} p 1$ transcription unit (with +1 being the mRNA start site) was fused to the phol ORF (Fig. 3). This plasmid generates vigorous acid phosphatase activity when introduced into a pho1s strain (Schwer et al. 2017). Acid phosphatase activity driven by the tgp 1 promoter reporter plasmid is reduced by $85 \%$ either: (i) in a pho7 $\Delta$ strain background; or (ii) by mutation of the Pho7 DNA binding site 5'-TCGGACATTCAA located at nucleotides -192 to -181 upstream of the $\operatorname{tgp} 1$ transcription start site (Schwer et al. 2017). The effects of CTD mutations on the activity of the $\operatorname{tg} p 1 \cdot p h o 1$ reporter are shown in Figure 3. Activity was nearly identical in the rpb1-CTD WT, T4A, and $S 5_{3} \cdot S 5 A_{11}$ strains. Thus, the de-repression of the $n c$-tgp1$\operatorname{tgp} 1 \cdot p h o 1$ locus seen in $S 5_{3} \cdot S 5 A_{11}$ cells is not reflective of increased activity of the $\operatorname{tg} p 1$ promoter per se. Whereas tgp 1 promoter-driven Phol expression in S7A was 38\% higher than in WT cells, this effect is much less than the fivefold increase in expression of Phol from the $n c$-tgp1-tgp $1 \cdot p h o 1$ reporter elicited by the $S 7 A$ allele.

\section{Effect of mutating DSR sequences in the nc-tgp1 IncRNA}

Ard et al. (2014) noted that the $n c$-tgp1 RNA contains a cluster of three putative DSR sequences in the region from 

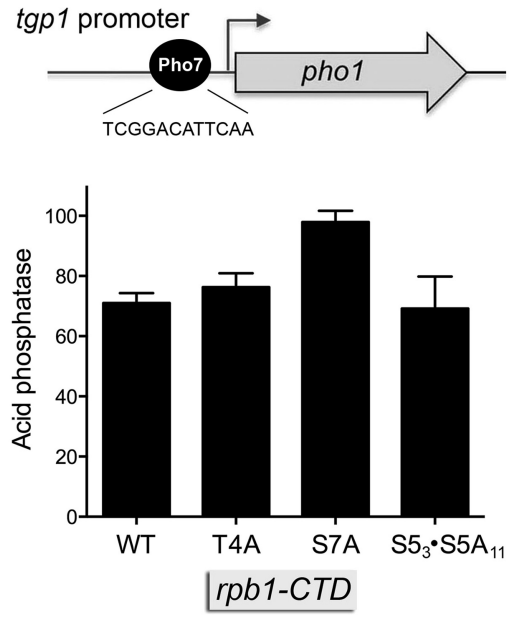

FIGURE 3. Effect of $r p b 1-C T D$ mutations on $\operatorname{tg} p 1$ promoter activity. A schematic of the -871 tgp1 promoter-driven pho1 reporter (Schwer et al. 2017) is shown at the top, with the Pho7 binding site in the tgpl promoter highlighted. Acid phosphatase activity of pho1 $\triangle$ rpb1-CTD-WT, rpb1$C T D-T 4 A$, rpb1-CTD-S7A, and $r p b 1-C T D-S 5_{3} S 5 A_{11}$ cells bearing the tgp $1 \cdot$ phol reporter plasmid is shown.

nucleotides +821 to +850 (highlighted in gold in Fig. $4 \mathrm{~A}$ ). Tandem DSRs promote RNA degradation via their recognition by the YTH-domain protein Mmil. The canonical DSR hexanucleotide sequence is $5^{\prime}$-U(U/C)AAAC (Yamashita et al. 2012). The first and third hexanucleotides in the putative DSR cluster of the $n c$-tgp 1 lncRNA conform to the UCAAAC consensus; the middle hexanucleotide is a single-base variant UUAAAA (Fig. 4A). It was shown previously that certain variant $\overline{D S R}$ hexanucleotide motifs can augment the function of the consensus DSR element to promote RNA elimination (Yamashita et al. 2012). However, 5' UUAAAA was not among the variant motifs tested. We have shown that the Mmil YTH domain binds equally well to RNA containing either a consensus UUAAAC hexamer or a UUAAAU variant (Chatterjee et al. 2016). Inspection of the $n c$-tgp 1 RNA sequence revealed three UUAAAU sequences and two UUAAAC sequences (highlighted in green in Fig. $4 \mathrm{~A})$ in addition to the DSR cluster.

To evaluate the role of the +821 to +850 DSR cluster in tgp1 regulation, we introduced compound mutations (at five out of six positions) into each of the three hexanucleotide motifs of the $n c$ - $\operatorname{tg} p 1-\operatorname{tg} p 1 \cdot p h o 1$ reporter (Fig. 4B). We gauged the effect of the DSR cluster mutation on the responsiveness to phosphate starvation, as reflected in the induction of acid phosphatase activity as a function of time after transfer to medium lacking phosphate. DSR mutation delayed the onset of acid phosphatase production by $1 \mathrm{~h}$, but did not affect the rate of acid phosphatase production thereafter (Fig. 4B).

Northern analysis of RNA isolated from phosphate-replete phol $\Delta$ cells bearing the wild-type $n c$-tgp $1-\operatorname{tg} p 1 \cdot p h o 1$ reporter plasmid showed that the $\sim 1.9 \mathrm{~kb} n c$-tgpl lncRNA was detect- able, but the downstream pho1 mRNA was not (Fig. 4C). We also detected a $\sim 0.7-\mathrm{kb}$ transcript that was recognized by the $n c$-tgp1 probe, which we refer to henceforth as $n c$-tgp1-short. (The ability to detect by northern blot the lncRNA, and the short RNA, expressed from the plasmid, but not from the chromosomal $n c$-tgp1 locus [Fig. 1B], likely reflects the high copy number of the fission yeast plasmid.) The salient finding was that the DSR cluster mutation elicited an increase in the abundance of the $n c-\operatorname{tg} 1 \operatorname{lncRNA}$ as well as the accumulation of a $\sim 4 \mathrm{~kb} n c$-tgp1-pho1 read-through transcript that annealed to the $n c$-tgp 1 and $p h o 1$ probes. These findings implicate the DSR cluster as a determinant of the stability of the $n c$ - $\operatorname{tgp} 1 \operatorname{lncRNA}$, and its propensity to terminate without read-through into the downstream gene. Note that the level of the nc-tgp1-short RNA was not increased by the DSR cluster mutation, presumably because the short transcript terminates upstream of the DSR cluster.

\section{Defining the $3^{\prime}$ end of the polyadenylated nc-tgp1 IncRNA}

We mapped the site of polyadenylation of the $n c$-tgp 1 lncRNA by $3^{\prime}$ RACE using as template total RNA isolated from two cellular sources that have $1.9 \mathrm{~kb} \operatorname{lncRNAs}$ detectable by northern analysis: (i) mmil $\Delta$ cells expressing $n c$ tgp1 from the native chromosomal locus (Fig. 1B, 4D); and (ii) pho1 $\Delta$ cells expressing $n c$-tgp 1 from the $n c$-tgp 1 (DSRWT)-tgp 1 pho1 reporter and nc-tgp1(DSR-mut)-tgp1・pho1 reporter plasmids (Fig. 4C,E). Sequencing of three, two, and four independent cDNA clones from these RNA sources, respectively, revealed (in all nine cases) identical junctions to a poly(A) tail at nucleotide 1636 of the lncRNA transcript, which is situated $17 \mathrm{nt}$ downstream from a fission yeast AAUAAA polyadenylation signal (Fig. 4F; Mata 2013). Thus, the same polyadenylated IncRNA is produced from the native $n c$-tgp1-tgp1 locus (Fig. 4D) and the nc-tgp1tgp1 pho1 reporter (Fig. 4E). The cleavage/poly(A) site of the $n c$-tgp $1 \operatorname{lncRNA}\left(5^{\prime}\right.$-UCGGA $\left.\downarrow\right)$ is located $187 \mathrm{nt}$ upstream of the tgp1 transcription start site, within the sequence that corresponds to the Pho7 DNA binding site of the tgpl promoter (5'-TCGGA $\downarrow$ CATTCAA). Thus, transcription across the poly(A) site of the $n c$-tgp 1 lncRNA excludes (or displaces) Pho7 binding at the $\operatorname{tg} p 1$ promoter.

\section{Defining the $3^{\prime}$ end of the polyadenylated nc-tgp1-short RNA}

We mapped the site of polyadenylation of the nc-tgp1-short RNA by $3^{\prime}$ RACE using as template total RNA isolated from yeast cells (not containing a plasmid) expressing $n c$ tgp1 from its natural context in the chromosome (10 independent cDNA clones sequenced), from phol $\Delta$ cells expressing $n c$-tgp 1 from the wild-type $n c$-tgp 1 -tgp $1 \cdot p h o 1$ reporter plasmid (15 independent cDNA clones sequenced), and from $p h o 1 \Delta$ cells expressing $n c$-tgp 1 from the $n c$-tgp 1(DSR- 
A

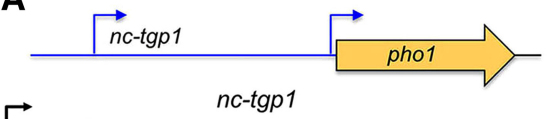

$\Gamma_{\text {GGAAACUUUUUAAAUUUUAUUUCUAUUUUUCUCUUGGGCAAUUUUUGCUUUGCUGUU }}$ UGGUUUGAGGUCAGUCGCCAAAGGCAAUAGCAUUGUGUGCAUGUGUGCAUGGUUAA AAUGAAAAGUUGGCUAACAACAUUUUUAUUCAAAAAUCAUUAACAUACAAAUCUAA UCAAAAACAAAAUGAAUAUAGUAAGCAACAAGAAUUAAAU CAUUUUUUUUUCAUUG UUUUAAUUUUAAUGAGUAAUUCCUUUCUUCAAUUCCUUAUUUUUUCAUCCUUCCAU UCAUUCAUUCAUGCAUUCCAUCAUUCCUCCUUGAUGCAAUGGAUCGCAUGGAUAUA CAUACAUUGAUUUGUGAAUCGUGUGCAUCUAUUGAUGGAUGGGAGUUGUAUGUGUU UGUGUGAUGAGGGUUUGUUGAAGCAAGGCAUUGUCGAGGAUGCCCUCUAUUUUGUG UUGUGUUUUAGAUUAAAAGUUUAAUGUGUUUAUCUCUUUAAUAUACAUUGUUACAC AAAAUCUCUGUUUAUGAUAUUCAUUUCGUUCCUAUAGUUUAUUCGAAUGAAUUGAA UUGAAUUGACUAGACUGACUAUGCAUACCAAUCUUGUUGCUUCUAUUGUUUAACGA AAUACGCAUAGAAUGCUCGGAUUGUCGACUUUAUCAUAGUUUUACGAAGUGAAAUU UUUUUAAAUGCUGCACUCACAUACUGACUGUGUGAUGUGAAAGAUGAAAGUGUCAU AUCAAAUUUAAUCAAAUGAACCCAAGGGAGAGUGAAUAUUAUGAAUUCACUCAUCC UUGAUGUUGGCAGAACGAGUCGUUUUGUCUGCAUAUUCAAACAACCCCCUUAAAAC UAUCUCAAACGAAACUAAACUCGGGCAUGCAUUUCAACGUUUUGCAUGGUCUAAUC AUUUUUUGCAUUGACUAUAUCUUUAUUUGCAUUUCACUAUAUUGUUUUGCACUUUA CUAGAUCGUUUUUGCAUCUAUGGUACGUUUUGCACUAAUGAAUUUUUUGCACUCAC UCAAUUUAAACUGCUUCCAAGAAUAAAACGUUUUUAUUUUUAUUUUUUUUCUUUU CCUUUGCCGUCCGUUGUUUGUCACCCUCAACUACACAAAAUAUCGACUCCGUGACU GUCAUGUUUUAUCUUUCACACGAAUGACGAUGAAAUGUGACAGUUUAUCUGGUCAG GAUGAUUGUACAGCCUGGGCCUUGGUUUGCAUACAAUUGAACGAAUUGUGAGUGAU UUAAUGGUGGUUAAUCUUAGAAAUACUAUAAUCUACUUCAACCAAUUCUAUUACUU CAUUUUUUGCUUUGCUGAUACGGCAUGGUUGCCUCAUGUGUAGGACAUUUGUCUGA CAAACCAAUUAUCCCUACACGGGAAGAGAAUUCCUUGGGUUAAACGGCAUG
B

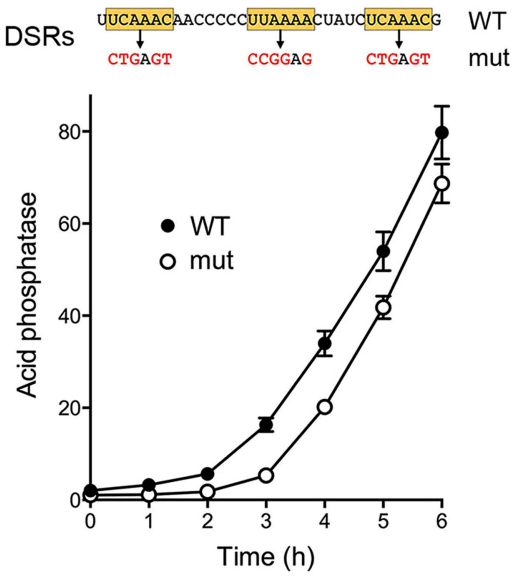

C

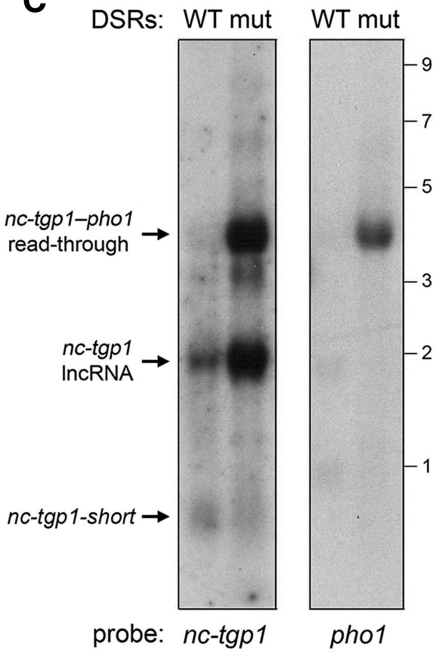

D

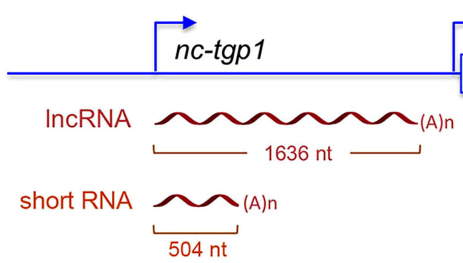

$\mathbf{F}$

InCRNA
GCUAAAAUGAACUUACGAAUAAAUCGCUUUUUCCUUCGGAa $17 \mathrm{nt}-$ poly(A) tail
Short RNA
UUAAUGUGUUUAUCUCUUUAAUAUACAUUGUUACACAAAAaaaaaaaaaa
E

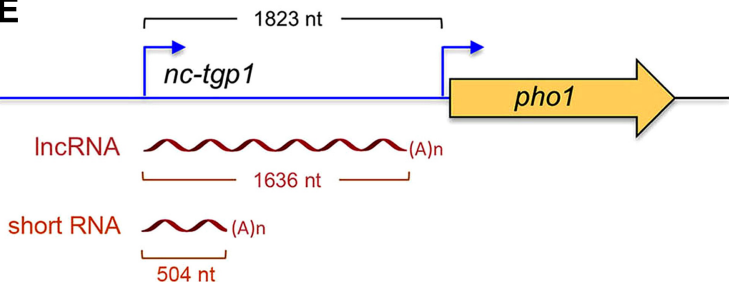

GURE 4. Characterization of the $n c$ - $\operatorname{tg} p 1$ lncRNA and a novel $n c$-tgp 1 short RNA. (A) The nucleotide sequence of the first $1395 \mathrm{nt}$ of the $n c$-tgp 1 lncRNA is shown. A cluster of three putative DSR sequences in the region from nucleotides +821 to +850 is highlighted in gold. Other DSR hexamers are highlighted in green. The polyadenylation signal for the $n c$-tgp1-short RNA is shown in white font on black background. $(B)$ Phosphate starvation response. The indicated mutated version of the +821 to +850 DSR cluster (mut) was introduced into the $n c$-tgp 1-tgp 1 pho1 reporter plasmid shown in panel $A$. Yeast pho1 $\Delta$ cells bearing the DSR WT or mut $n c$-tgp1-tgp $1 \cdot p h o 1$ plasmids were assayed for acid phosphatase activity immediately prior to and at hourly intervals after transfer to medium lacking exogenous phosphate. $(C)$ Northern blotting. Total RNA from pho1 $\Delta$ cells bearing the DSR WT or mut $n c$-tgp1-tgp $1 \cdot p h o 1$ plasmids was resolved by agarose gel electrophoresis, transferred to membrane, and probed with ${ }^{32} \mathrm{P}$-labeled $n c$-tgp 1 (left panel) and pho1 (right panel) DNAs. The positions and sizes (kb) of RNA size markers are indicated on the right. (D-F) Mapping the $3^{\prime}$ ends of the polyadenylated $n c$-tgp 1 lncRNA by $3^{\prime}$ RACE of RNA from mmil $\Delta$ cells expressing $n c$-tgp 1 from the native chromosomal locus (panel $D$; sequencing three independent cDNA clones), and pho1 $\Delta$ cells expressing $n c$-tgp 1 from the $n c$-tgp $1(D S R-W T)-\operatorname{tgp} 1 \cdot p h o 1$ and $n c$-tgp1(DSR-mut)-tgp1 $\bullet$ pho1 reporter plasmids (panel $E$; sequencing two and four independent cDNA clones, respectively). $(D-F)$ Mapping the $3^{\prime}$ ends of the polyadenylated $n c$-tgp1-short RNA by $3^{\prime}$ RACE of RNA from cells expressing $n c$-tgp 1 from the native chromosomal locus (sequencing 10 independent cDNA clones), and pho1 $\Delta$ cells expressing $n c$-tgp 1 from the $n c$-tgp1(DSR-WT)-tgp1 $\cdot p h o 1$ and $n c$-tgp 1 (DSR-mut)-tgp1 phol reporter plasmids (sequencing 15 and 2 independent cDNA clones, respectively). $(F)$ The lncRNA and short RNA sequences preceding the poly(A) tails are shown. Poly $(\mathrm{A})$ nucleotides are depicted in lower case font. A canonical fission yeast polyadenylation signal is shown in white font on black background.

mut)-tgp1 $\bullet$ pho1 reporter plasmid (two independent cDNA clones sequenced). The RACE analysis revealed identical junctions in all 27 cases to a poly(A) tail at nucleotide 504-508 of the nc-tgp1-short transcript, the ambiguity being that the poly $(\mathrm{A})$ tail overlaps with four consecutive templated A nucleotides (Fig. 4F). The short RNA poly(A) site is situated downstream from overlapping fission yeast UUUAAU and UUAAUA polyadenylation signals (Fig. 4F; Mata 2013).

\section{Mutating the poly(A) signal of the nc-tgp1-short RNA abolishes de-repression of the tgp1 promoter by CTD S5A mutation}

Our detection of a novel short poly $(\mathrm{A})^{+}$RNA derived from the $n c$-tgp 1 gene adds a new wrinkle to the $n c$-tgp 1 story. Most pertinent is the fact that Pol2 elongation complexes synthesizing the $n c$-tgp1-short RNA will undergo nascent strand $3^{\prime}$ cleavage, and (in all likelihood) ensuing 
transcription termination (Loya and Reines 2016) well upstream of the Pho7 binding site of the tgp1 promoter [which coincides with the lncRNA poly(A) site] (Fig. 4D). This scenario raises the prospect that poly $(\mathrm{A})$ site choice might modulate lncRNA activity. For example, a change in poly(A) site choice skewed toward $n c$-tgp 1 -short might contribute to the observed de-repression of the downstream tgp 1 promoter in phosphate-replete cells with $S 5_{3} \cdot S 5 A_{11}$ phospho-site mutations in the Pol2 CTD (Fig. 1F). If this is the case, then we would expect that the de-repressive effects of this CTD allele on the tgp 1 promoter in the $n c$-tgp1-tgp $1 \cdot p h o 1$ reporter should be effaced by mutation of the $n c$-tgp1-short RNA polyadenylation signal (PAS). Indeed, this was precisely what occurred when we changed the nc-tgp1-short PAS in the DNA template from TTAATA (wild-type) to CCGGCG (mutant) (Fig. 5A) and gauged tgp 1 promoter-driven acid phosphatase expression in phosphate-replete $S 5_{3} \cdot S 5 A_{11}$ cells (Fig. 5B). These results indicate that the reduction in CTD Ser5 phospho-sites exerts its de-repressive effect via the nc-tgp1-short PAS.

To directly assess poly(A) site choice, we performed RNase probe protection analysis of RNA isolated from $r p b 1-C T D$ $W T$ and $-S 5_{3} \cdot S 5 A_{11}$ cells bearing the $n c$-tgp1-tgp $1 \cdot p h o 1$ reporter with a wild-type or mutant nc-tgp1-short PAS. The 170-nt wild-type ${ }^{32} \mathrm{P}$-UMP-labeled RNA probe (Fig. 5C, lane1) is complementary to the wild-type $n c$-tgp 1 lncRNA throughout a 133-nt segment that spans the $3^{\prime}$ cleavage/polyadenylation site of the $n c$-tgp1-short RNA. RNase T1 cleavage of any probe annealed to lncRNA yields a 138-nt protected fragment; cleavage of probe annealed to the polyadenylated $n c$-tgp1-short RNA yields a shorter 86-nt protected fragment (Fig. 5C, lanes 3-6). Protection of these two fragments from T1 digestion depended on prior annealing to RNA from cells bearing the PAS-WT reporter (Fig. 5C, lane 2). The presence in all RNase digests of a 43-nt T1-resistant fragment corresponding to the longest interval between $G$ nucleotides of the labeled probe (lanes 3-6), affirmed that the probe was present in excess over the complementary cellular $n c$-tgp 1 RNAs. The probe protection analysis revealed that utilization of the short PAS site increased in the rpb1-CTD-S5 ${ }_{3} \cdot S 5 A_{11}$ strain (lanes 5,6) vis à vis the wild-type (lanes 3,4 ). The ratio of the $n c$-tgp1-short to lncRNA T1-protected fragments is a measure of $n c$-tgp1-short PAS choice. The short RNA/lncRNA ratio values (mean \pm SEM of RNA preparations from three independent yeast cultures, with two technical replicates of the RNase protection for each RNA sample) were $0.955 \pm$ 0.03 for the rpb1-CTD-WT strain and $1.92 \pm 0.03$ for the $r p b 1-C T D-S 5_{3} \cdot S 5 A_{11}$ strain. Control experiments using a probe complementary to the $n c$-tgp 1 transcript with the mutant nc-tgp1-short PAS (lane 7) affirmed that the PAS

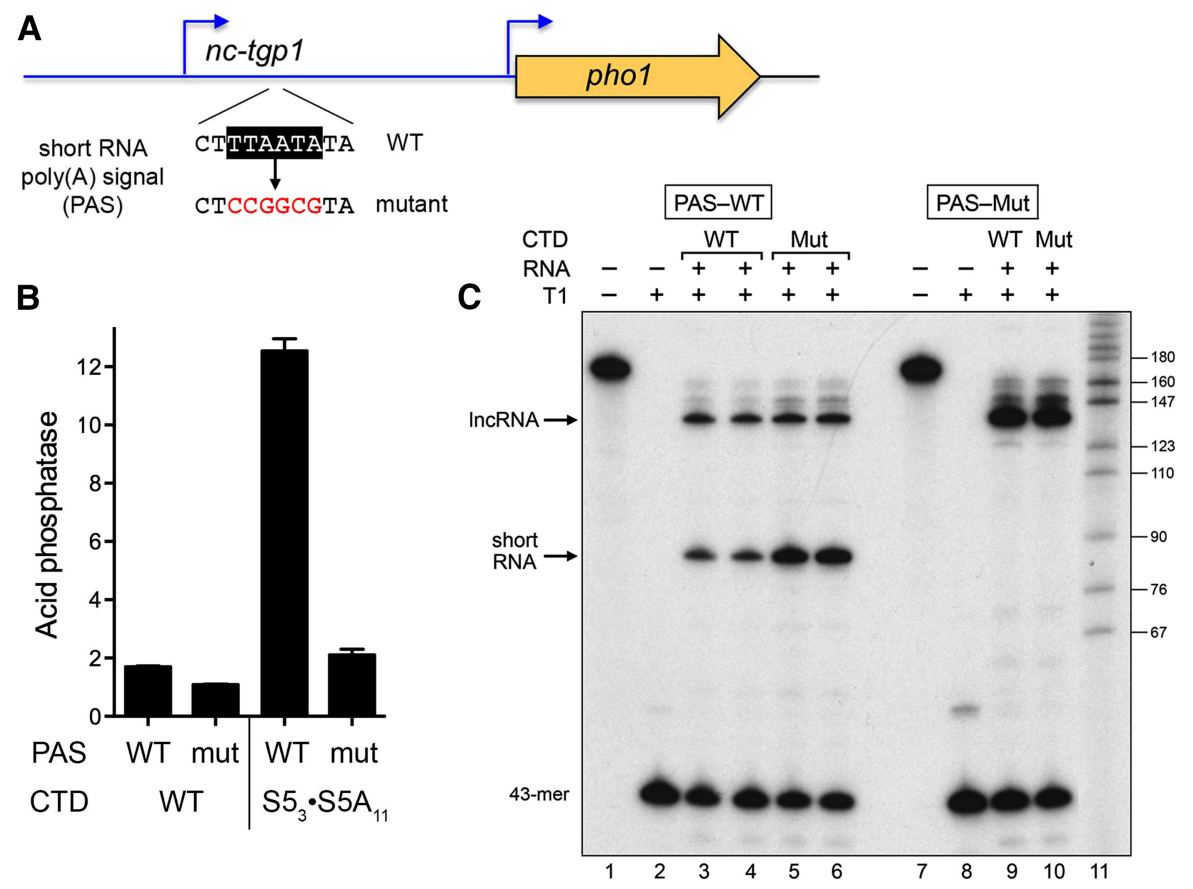

FIGURE 5. Mutating the poly(A) signal of the $n c$-tgp1-short RNA abolishes de-repression of the tgp 1 promoter by CTD S5A mutation. (A) The short RNA polyadenylation signal (PAS) in the $n c$ - $\operatorname{tgp} 1-\operatorname{tgp} 1 \cdot p h o 1$ reporter cassette (highlighted in white font on black background) was replaced by the mutant sequence shown in red font below the wild-type PAS. (B) Acid phosphatase activity of pho1 $\Delta r p b 1-C T D-W T$ or $r p b 1-C T D-S 5_{3} S 5 A_{11}$ cells bearing $n c$-tgp 1-tgp 1 •pho1 reporter plasmids with wild-type (WT) or mutant (mut) short RNA PAS elements. (C) RNase protection analysis of $n c$-tgp1short PAS utilization in rpb1-CTD-WT cells (CTD WT; lanes 3,4,9) or rpb1-CTD-S5 $35 A_{11}$ cells (CTD Mut; lanes 5,6,10) bearing nc-tgp1-tgp1-pho1 reporter plasmids with wild-type (PAS-WT; lanes 3-6) or mutant (PAS-Mut; lanes 9,10) short RNA PAS elements was performed as described in Materials and Methods. The RNase T1-digested samples (T1+) and untreated controls (T1-; lanes 1,7) were analyzed by denaturing PAGE. The positions and lengths (nt) of radiolabeled DNA size markers (lane 11) are indicated on the right. 
mutation effaced the shorter protected species and yielded exclusively a signal for the $n c$-tgp 1 lncRNA (Fig. 5C, lanes 9,10).

\section{Mutating the poly(A) signal of the nc-tgp1-short RNA attenuates the tgp1 phosphate starvation response}

We gauged the effect of the inactivating TTAATA (wild-type) to CCGGCG (mutant) change in the $n c$-tgp 1 -short RNA PAS on the kinetics of tgp 1 promoter-driven acid phosphatase expression from the $n c$-tgp1-tgp $1 \cdot p h o 1$ reporter during phosphate starvation. The PAS mutation elicited a delay in the onset of Phol accumulation and a decrement in the rate of Phol production during the $6 \mathrm{~h}$ interval after transfer of the cells to phosphate-free medium (Fig. 6), e.g., such that the acid phosphatase activity of PAS-Mut cells at $5 \mathrm{~h}$ poststarvation was equivalent to the activity of PAS-WT cells after $3 \mathrm{~h}$ of starvation. These results imply that transcription from the $n c$-tgp 1 promoter persists during phosphate starvation (at least during the time frame analyzed) to an extent that a $n c$ tgp1-short PAS mutation, which biases toward nc-tgp1 lncRNA synthesis, significantly blunts tgp 1 promoter activity. The fact that a PAS mutation does not completely prevent tgp 1 promoter induction during phosphate starvation suggests that there is also a component of $n c$-tgp 1 promoter down-regulation in phosphate homeostasis.
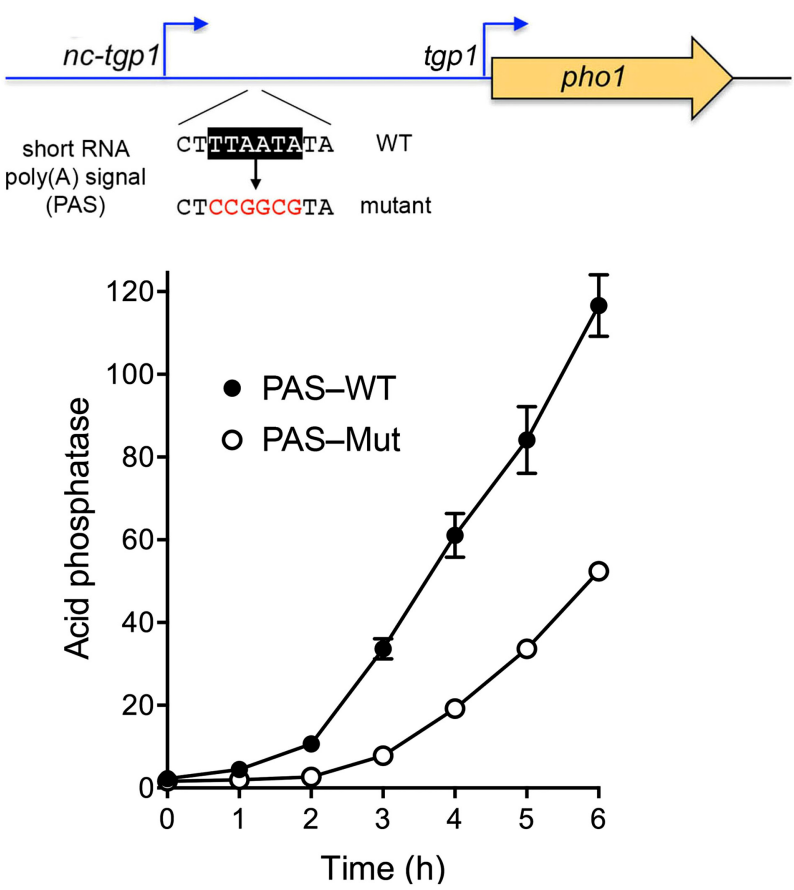

FIGURE 6. Mutating the poly(A) signal of the $n c$-tgp1-short RNA attenuates the induction of the tgp 1 promoter during phosphate starvation. Cells bearing the $n c$-tgp1-tgp $1 \cdot p h o 1$ reporter in which the $n c$ tgp1-short RNA polyadenylation signal (PAS) was either wild-type or mutant were assayed for acid phosphatase activity immediately prior to and at hourly intervals after transfer to medium lacking exogenous phosphate.

\section{DISCUSSION}

\section{IncRNA repression of phosphate-starvation genes in fission yeast}

Fission yeast phosphate homeostasis entails repressing the tgp1 and pho1 genes during phosphate-replete growth and inducing/de-repressing them under conditions of phosphate starvation. Here we contribute to an emerging appreciation of the role of lncRNAs transcribed co-directionally from upstream $n c$-tgpl and prt genomic loci flanking tgpl and $p h o 1$ in enforcing the repressive status, in particular by delineating shared features that govern transcription of the $n c$-tgp 1 and prt lncRNAs. Within the $n c$-tgp 1 promoter, there are two essential elements: a HomolD box $\left({ }^{-64} \mathrm{CAGTCACA}^{-57}\right)$ and a TATA box $\left({ }^{-30}\right.$ TATATATA $\left.^{-23}\right)$. We find that mutations in either the HomolD or TATA sequences in the context of the $n c$ $\operatorname{tg} p 1-\operatorname{tg} p 1$ reporter result in de-repression of the $\operatorname{tg} p 1$ promoter in phosphate-replete cells. HomolD and TATA elements are also present and positioned similarly in the prt lncRNA promoter, where they are important for prt-dependent repression of phol expression (Chatterjee et al. 2016), and in the promoter for the $S$. pombe U3 snoRNA (Nabavi and Nazar 2008).

Our results focus attention on the HomolD element as a likely target of phosphate responsiveness, whereby HomolD functions positively in $n c$-tgp 1 lncRNA transcription when phosphate is available, presumably via binding of an activating transcription factor to the HomolD sequence. Because loss of $n c$-tgp1 and prt transcription suffices to de-repress tgp 1 and phol, the simplest model for phosphate starvation-induced tgpl and phol expression is that starvation elicits a signaling pathway that eventually shuts off the $n c-\operatorname{tgp} 1$ and prt promoters (Ard et al. 2014; Chatterjee et al. 2016), conceivably by an inactivating modification of the transcription factor that recognizes HomolD in the lncRNA promoters. Maldonado and colleagues have shown that the HomolD sequence is recognized by the essential fission yeast transcription factor Rrn7 (Rojas et al. 2011) and that phosphorylation of Rrn7 by casein kinase 2 (CK2) inhibits its ability to bind to HomolD DNA in vitro (Moreira-Ramos et al. 2015). By mutating three predicted CK2 phosphorylation sites in Rrn7 to alanine, they showed that (i) replacing Thr67 with alanine uniquely eliminated its CK2 phosphorylation in vitro; and (ii) binding of Rrn7-T67A to HomolD DNA was unaffected by CK2 (Moreira-Ramos et al. 2015). We reasoned that if Rrn7 Thr67 phosphorylation during phosphate starvation is the basis for shut-off of HomolD-driven lncRNA transcription, then prevention of such phosphorylation by T67A mutation might block the starvation induction of phosphateresponsive genes. Therefore, we disrupted the native S. pombe $r r n 7^{+}$gene in a diploid strain by insertion of a $u r a 4^{+}$marker and introduced a mutant $r r n 7-T 67 A$ allele at the leu1 locus. After sporulation to obtain a haploid rrn7::ura4 ${ }^{+}$leu1::rrn7T67A strain, we verified that the $r r n 7-T 67 A$ strain grew as 
well as $r r n 7^{+}$on YES medium. Testing for induction of Pho1 phosphatase activity upon shift to phosphate-free medium showed no effect of $r r n 7-T 67 A$ on the extent of Phol accumulation (not shown), leading us to surmise that Rrn7 Thr67 phosphorylation is not a decisive event in the phosphate starvation response.

Our experiments illuminate key properties of the $n c$-tgpl lncRNA. For example, whereas it had been noted earlier that the lncRNA contains a cluster of three DSR-like hexanucleotide elements that are recognized by Mmil (Ard et al. 2014; Kilchert et al. 2015), the contribution of these DSRs to regulated $\operatorname{tg} p 1$-driven transcription was not addressed. Here we showed that mutating the DSR cluster resulted in a higher steady-state level of the $n c$ - $\operatorname{tg} p 1$ lncRNA and the accumulation of a longer read-through transcript spanning the lncRNA and the downstream tgp 1 promoter-driven phol reporter. (These effects of $n c$-tgp1 DSR mutations on the plasmid reporter echoed those of mmil $\Delta$ on the chromosomally transcribed $n c$-tgpl lncRNA and $n c$-tgp1-tgpl read-through RNA.) The lack of effect of the DSR mutations on the activity of the downstream tgp1 promoter in phosphate-replete cells simply reflects the fact that the $\operatorname{tg} p 1$ promoter is already maximally repressed by transcription of the wild-type $n c$-tgp 1 lncRNA. However, the DSR mutations do elicit a $1 \mathrm{~h}$ delay in the induction of tgpl promoter-driven expression after phosphate starvation. In contrast, DSR cluster mutations in the prt lncRNA cause a significant decrement in the basal level of Phol expression in phosphate-replete cells and they cause a longer 2-h delay in the induction of Phol after phosphate starvation (Chatterjee et al. 2016).

The poly $(\mathrm{A})$ site of the $n c$-tgp1 lncRNA is located $187 \mathrm{nt}$ upstream of the $\operatorname{tgp} 1$ transcription start site and directly overlaps the binding site for transcription factor $\mathrm{Pho} 7$ in the tgp 1 promoter (Fig. 4D). The salient point here is that Pol2 elongation complexes synthesizing the $n c$ - $\operatorname{tg} p 1 \operatorname{lncRNA}$ will fully traverse the $\operatorname{tg} p 1$ promoter. Thus, the simplest model for repression posits that $n c$-tgp 1 lncRNA synthesis interferes with $\operatorname{tgp} 1$ promoter function by displacing $\mathrm{Pho} 7$ from the promoter DNA, via collision with Pol2 traveling on the segment of the $n c$-tgp1 template that includes the Pho7 recognition site. An alternative view is that lncRNA transcription causes changes in chromatin status over the tgp 1 promoter (albeit not via heterochromatin) that interfere with $\mathrm{Pho} 7$ binding (Ard and Allshire 2016). These views are not mutually exclusive, e.g., displacement of Pho7 by Pol2 transcribing $n c$-tgp 1 could incite changes in nucleosome density over the tgp1 promoter.

\section{Comparison to regulated SER3 expression in budding yeast}

The repression of the phosphate-responsive $\operatorname{tg} p 1$ gene in fission yeast by transcription of an upstream lncRNA echoes themes established for regulated SER3 expression in $S$. cerevisiae, whereby SER3 is tightly repressed during growth in rich medium via transcription of the upstream SRG1 lncRNA so as to interfere with the SER3 promoter (Martens et al. 2004). As seen here for $n c$-tgp1: (i) The size of the polyadenylated SRG1 lncRNA is such that its $3^{\prime}$ end overlaps the SER3 promoter; and (ii) mutation of the TATA box in the SRG1 promoter de-represses SER3 (Martens et al. 2004). SRG1 transcription is regulated by serine availability, i.e., SRG1 is turned on under serinerich conditions and shut off in response to acute serine starvation, with SER3 expression anti-correlating to that of SRG1 (Martens et al. 2004). Whereas fission yeast $n c$-tgp1 lncRNA expression is driven by a HomolD element in its promoter, the cognate transcription factor(s) of which remain unclear absent genetic evidence for a role of Rrn7, budding yeast SRG1 expression is activated by a DNA element that contains a binding site for transcription factor Cha4 (Martens et al. 2005). Deletion of Cha4 suppresses SRG1 expression and consequently de-represses SER3 in serine-rich medium (Martens et al. 2005). It is noteworthy that budding yeast Cha4 is a member of the $\mathrm{Zn}_{2} \mathrm{Cys}_{6}$ family of fungal transcription regulators (Holmberg and Schjerling 1996), as is S. pombe Pho7 (Schwer et al. 2017). Thus, whereas budding yeast deploys a $\mathrm{Zn}_{2} \mathrm{Cys}_{6}$ factor to transcribe the lncRNA and thereby enforce the repressive state of the flanking gene, fission yeast uses a $\mathrm{Zn}_{2} \mathrm{Cys}_{6}$ factor to transcribe the flanking target gene once the repressive effect of the lncRNA is alleviated.

\section{Influence of nc-tgp1-short RNA and CTD status}

A short poly $(\mathrm{A})^{+}$RNA derived from the $n c$-tgp 1 gene adds another layer of control to the system. The poly $(A)$ site of the nc-tgp1-short RNA is located 504-508 nt from the transcription start site, well upstream of the DSR cluster present in the lncRNA. Pol2 elongation complexes that synthesize the $n c$-tgp1-short RNA are expected to terminate transcription well upstream of the $\mathrm{Pho} 7$ site of the $\operatorname{tgp} 1$ promoter. Thus, transcription of the $n c$-tgp1-short RNA would not elicit repression of the downstream tgp 1 gene, which raised a hypothesis that poly(A) site choice might figure in the regulation of lncRNA function. Indeed, we show here that poly $(\mathrm{A})$ site choice biased toward nc-tgp1-short contributes to the derepression of the downstream tgp 1 promoter in phosphatereplete cells bearing S5A mutations in the Pol2 CTD, and that de-repression of the $\operatorname{tgp} 1$ promoter by the $r p b 1-C T D$ $S 5_{3} \cdot S 5 A_{11}$ allele is eliminated by mutation of the $n c$-tgp 1 short RNA poly(A) signal. In the same vein, the de-repression of the tgp 1 promoter by $r p b 1-C T D-S 7 A$ (Fig. $1 \mathrm{~F}$ ) is also eliminated by mutation of the $n c$-tgp 1 short RNA poly $(\mathrm{A})$ signal (not shown). We find that mutation of the nc-tgp1-short RNA poly(A) signal attenuates induction of the downstream tgp 1 promoter in phosphate-starved cells, both with respect to the lag time to see an increase in gene expression (gauged by acid phosphatase reporter activity) and the rate of acid phosphatase accumulation. 
Finally, our results reveal a new aspect of the fission yeast CTD code, in which the Ser5 phospho-site (and presumably its phosphorylation) disfavors a proximal poly(A) site in the $n c$-tgp 1 transcription unit, whereas reducing available Ser5 phospho-sites by $S 5 A$ mutation enhances proximal poly(A) site choice. Recent studies by the Bachand laboratory have implicated the fission yeast protein Seb1 in the regulation of cotranscriptional PAS selection in coding and noncoding genes (Lemay et al. 2016; Larochelle et al. 2017). Seb1 is an RNA binding protein, essential for vegetative growth, that recognizes a $5^{\prime}-(\mathrm{A} / \mathrm{U}) \mathrm{GUA}(\mathrm{A} / \mathrm{G})$ motif situated 50 - to $100-\mathrm{nt}$ downstream from sites of cleavage/polyadenylation (Lemay et al. 2016). Seb1 also interacts with the Pol2 CTD, though available evidence weighs against a role for the Ser5- $\mathrm{PO}_{4}$ mark in Seb1 recruitment and function (Lemay et al. 2016). Of note, whereas there are three distinct Seb1 motifs within the 100-nt segment downstream from the cleavage/polyadenylation site of the $n c-\operatorname{tgp} 1$ lncRNA, there are, in contrast, no Seb1 motifs flanking the cleavage/polyadenylation site of the $n c$-tgp1-short RNA (i.e., the nearest GUA sequence is $466 \mathrm{nt}$ downstream from the short RNA cleavage/polyadenylation site). These considerations militate against Seb1 as an agent of Ser5-regulated usage of the $n c$-tgp1-short poly $(\mathrm{A})$ site.

\section{MATERIALS AND METHODS}

\section{Reporter plasmids}

We constructed three sets of pho1-based reporter plasmids, marked with a kanamycin-resistance gene ( $k a n M X)$, in which the expression of Phol acid phosphatase was driven by either: (i) a tandem $n c$-tgp 1 (promoter+lncRNA)-tgp 1(promoter) element; (ii) a $n c$-tgp 1 (promoter) element; (iii) or a tgp 1 (promoter) element. These were derivatives of $\mathrm{pKAN}$-(pho1) described previously (Chatterjee et al. 2016) generated by insertion of genomic sequences flanking pho1, as follows. Plasmid $\mathrm{pKAN}$-(nc-tgp1-tgp1 $1_{\text {prom }}$ pho1) includes a fragment of the $n c$-tgp1-tgp1 locus, spanning $301 \mathrm{nt}$ upstream of the $n c$-tgp 1 transcription initiation site (encompassing the putative $n c$-tgp 1 promoter) and the entire 1865-nt segment between the nc-tgp 1 transcription start site and the tgpl translation start codon (containing the putative tgp 1 promoter) fused to the phol ORF and its native $3^{\prime}$ flanking DNA. Plasmid $\mathrm{pKAN}$ - $\left(n c-\operatorname{tg} p 1_{\text {prom }} \bullet\right.$ pho1 $)$ includes the 301 nt upstream of the $n c$ - $\operatorname{gg} p 1$ transcription initiation site fused to the phol ORF and its native $3^{\prime}$ flanking DNA. Plasmid pKAN-(tgp $1_{\text {prom- }}$ -pho1) includes the 913-nt segment upstream of the tgp 1 translation start codon fused to the phol ORF and its native $3^{\prime}$ flanking DNA. Serial truncations from the $5^{\prime}$ end of the $n c$-tgp 1 promoter were gen-

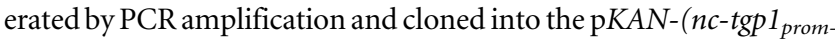
-pho1) reporter in lieu of the original promoter segment. Nucleotide substitutions were introduced into the reporter constructs by twostage overlap extension PCR amplification with mutagenic primers, followed by insertion in lieu of the wild-type DNA segments. The inserts of all plasmids were sequenced to exclude unwanted mutations.

\section{Reporter assays}

Reporter plasmids were transfected into pho1s cells (Chatterjee et al. 2016). kanMX transformants were selected on YES (yeast ex- tract with supplements) agar medium containing $150 \mu \mathrm{g} / \mathrm{mL}$ G418. Single colonies of transformants $(\geq 20)$ were pooled and grown at $30^{\circ} \mathrm{C}$ in plasmid-selective liquid medium. Aliquots of exponentially growing cultures were harvested, washed, and suspended in water to attain $A_{600}$ of 1.25 or 2.5. To quantify acid phosphatase activity, reaction mixtures $(200 \mu \mathrm{L})$ containing 100 $\mathrm{mM}$ sodium acetate ( $\mathrm{pH} 4.2), 10 \mathrm{mM}$-nitrophenylphosphate, and cells (ranging from 0.01 to $1 A_{600}$ units) were incubated for 5 $\min$ at $30^{\circ} \mathrm{C}$. The reactions were quenched by adding $1 \mathrm{~mL}$ of $1 \mathrm{M}$ sodium carbonate; the cells were removed by centrifugation, and the absorbance of the supernatant at $410 \mathrm{~nm}$ was measured. Acid phosphatase activity is expressed as the ratio of $A_{410}$ ( $p$-nitrophenol production) to $A_{600}$ (cells). Each datum in the graphs is the average $( \pm$ SEM) of phosphatase assays using cells from at least three independent cultures. To test the responsiveness of Phol expression to phosphate starvation, cells transformed with pKAN-(nc-tgp1$\operatorname{tgp} 1_{\text {prom }} \cdot$ pho1) were grown in YES+G418 liquid medium, aliquots of exponentially growing cultures were harvested, washed in water, and adjusted to $A_{600}$ of $\sim 0.3$ in PMG (phthalate medium glutamate) + G418 liquid medium without phosphate. After incubation for various times at $30^{\circ} \mathrm{C}$, cells were harvested, washed, and assayed for acid phosphatase activity as described above.

\section{RNA analyses}

Total RNA was extracted via the hot phenol method from $20 A_{600}$ units of yeast cells that had been grown at $30^{\circ} \mathrm{C}$ in YES, YES + G418 (for selection of kanMX plasmids), or PMG without phosphate. The RNAs were treated with DNase I, extracted serially with phenol:chloroform and chloroform, and then precipitated with ethanol. The RNAs were resuspended in $10 \mathrm{mM}$ Tris- $\mathrm{HCl}$ (pH 6.8), 1 mM EDTA. For northern blotting, equivalent amounts $(10 \mu \mathrm{g})$ of total RNA were resolved by electrophoresis through a $1.2 \%$ agarose/ formaldehyde gel. After photography under UV illumination to visualize ethidium-bromide-stained $18 \mathrm{~S}$ and $28 \mathrm{~S}$ rRNAs, the gel contents were transferred to a Hybond-XL membrane (GE Healthcare). Gene-specific probes were prepared by radiolabeling DNA fragments of the tgp1 (nucleotides 151-1064), nc-tgp1 (nucleotides 1-1141), or pho1 (nucleotides 590-1293) genes. Hybridization was performed as previously described (Herrick et al. 1990) and the hybridized probes were visualized by autoradiography.

For amplification of cDNA $3^{\prime}$ ends, we used the $3^{\prime}$ RACE Kit (Invitrogen). In brief, $2 \mu \mathrm{g}$ of total RNA was used as template for first strand cDNA synthesis by SuperScript II RT and an oligo(dT) adapter primer (AP). The RNA template was removed by digestion with RNase $\mathrm{H}$, and the cDNA was then diluted 10-fold for amplification by PCR using gene-specific forward primers and an abridged universal reverse primer (AUAP). The PCR products were gel-purified, cloned into a pCRII TOPO vector by using the TOPO TA Cloning Kit (Invitrogen). Plasmid DNAs isolated from individual bacterial transformant colonies were sequenced. cDNAs were deemed to be "independent" when they contained different lengths of poly(dA) at the cloning junction.

\section{Assay of nc-tgp1 poly(A) site choice by RNase protection}

To generate RNA probes for hybridization, a 134-bp DNA fragment (from nucleotides +424 to +558 of the $n c$-tgp 1 transcription 
unit) spanning the poly(A) site of wild-type $n c$-tgp1-short RNA was amplified by PCR using primers that introduced restriction sites for cloning into the pGEM1 vector. An equivalent fragment containing the mutated polyadenylation signal was also cloned into pGEM1. The plasmids were linearized and used as templates for the in vitro synthesis of ${ }^{32} \mathrm{P}$-UMP labeled anti-sense transcripts by T7 RNA polymerase. The RNAs were gel-purified and aliquots $\left(3-4 \times 10^{4} \mathrm{cpm}\right)$ were coprecipitated with $10 \mu \mathrm{g}$ of total RNA from $\mathrm{p} K A N$-(nc-tgp1-tgp $1_{\text {prom }} \cdot$ pho1)-bearing pho1s rpb1-CTD-WT or rpb1-CTD-S5 ${ }_{3} \cdot S 5 A_{11}$ cells. After ethanol precipitation, the RNA pellets were dissolved in $20 \mu \mathrm{l}$ hybridization buffer (80\% formamide, $40 \mathrm{mM}$ PIPES $\mathrm{pH} 6.4,1 \mathrm{mM}$ EDTA, $400 \mathrm{mM} \mathrm{NaCl}$ ), heated at $80^{\circ} \mathrm{C}$ for $10 \mathrm{~min}$, and then incubated at $42^{\circ} \mathrm{C}$ for $12-15$ h. Following hybridization, $200 \mu \mathrm{L}$ of RNase $\mathrm{T} 1(0.5 \mathrm{U}$ in 10 mM Tris- $\mathrm{HCl}, \mathrm{pH}$ 7.4, $300 \mathrm{mM} \mathrm{NaCl}, 5 \mathrm{mM}$ EDTA) was added and the mixture was incubated at room temperature for $30 \mathrm{~min}$. Digestion was quenched by adding $10 \mu \mathrm{L}$ of $10 \%$ SDS. The samples were extracted with phenol:chloroform, ethanol precipitated, and analyzed by denaturing PAGE.

\section{SUPPLEMENTAL MATERIAL}

Supplemental material is available for this article.

\section{ACKNOWLEDGMENTS}

This research was supported by National Institutes of Health (National Institute of General Medical Sciences) grant GM52470 (to S.S. and B.S.). We thank Dr. T. Sugiyama for the mmils mei4-P527 strain.

Received September 8, 2017; accepted November 9, 2017.

\section{REFERENCES}

Ard R, Allshire RC. 2016. Transcription-coupled changes to chromatin underpin gene silencing by transcriptional interference. Nucleic Acids Res 44: 10619-10630.

Ard R, Tong P, Allshire RC. 2014. Long non-coding RNA-mediate transcriptional interference of a permease gene confers drug tolerance in fission yeast. Nat Commun 5: 5576.

Carter-O'Connell I, Peel MT, Wykoff DD, O’Shea EK. 2012. Genomewide characterization of the phosphate starvation response in Schizosaccharomyces pombe. BMC Genomics 13: 697.

Chatterjee D, Sanchez AM, Goldgur Y, Shuman S, Schwer B. 2016. Transcription of lncRNA prt, clustered prt RNA sites for Mmil binding, and RNA polymerase II CTD phospho-sites govern the repression of phol gene expression under phosphate-replete conditions in fission yeast. RNA 22: 1011-1025.

Gross T, Käufer NF. 1998. Cytoplasmic ribosomal protein genes of the fission yeast Schizosaccharomyces pombe display a unique promoter type: a suggestion for nomenclature of cytoplasmic ribosomal proteins in databases. Nucleic Acids Res 26: 3319-3322.

Harigaya Y, Tanaka H, Yamanaka S, Tanaka K, Watanabe Y, Tsutsumi C, Chikashige Y, Hiraoka Y, Yamashita A, Yamamoto M. 2006. Selective elimination of messenger RNA prevents an incidence of untimely meiosis. Nature 442: 45-50.

Henry TC, Power JE, Kerwin CL, Mohammed A, Weissman JS, Cameron DM, Wykoff DD. 2011. Systematic screen of Schizosaccharomyces pombe deletion collection uncovers parallel evolution of the phosphate signal pathways in yeasts. Eukaryot Cell 10: 198-206.
Herrick D, Parker R, Jacobson A. 1990. Identification and comparison of stable and unstable RNAs in Saccharomyces cerevisiae. Mol Cell Biol 10: 2269-2284.

Holmberg S, Schjerling P. 1996. Cha4p of Saccharomyces cerevisiae activates transcription via serine/threonine response elements. Genetics 144: $467-478$.

Kilchert C, Wittmann S, Passoni M, Shah S, Granneman S, Vasiljeva L. 2015. Regulation of mRNA levels by decay-promoting introns that recruit the exosome specificity factor Mmil. Cell Rep 13: 2504-2515.

Larochelle M, Hunyadkürti J, Bachand F. 2017. Polyadenylation site selection: linking transcription and RNA processing via a conserved carboxy-terminal domain (CTD)-interacting protein. Curr Genet 63: 195-199.

Lee NN, Chalamcharia VR, Reyes-Turce F, Mehta S, Zofall M, Balachandran V, Dhakshnamoorthy J, Taneja N, Yamanaka S, Zhou M, Grewal S. 2013. Mtr4-like protein coordinates nuclear RNA processing for heterochromatin assembly and for telomere maintenance. Cell 155: 1061-1074.

Lemay JF, Marguerat S, Larochelle M, Liu X, van Nues R, Hunyadkürti J, Hoque M, Tian B, Granneman S, Bähler J, et al. 2016. The Nrd1-like protein Seb1 coordinates cotranscriptional $3^{\prime}$ end processing and polyadenylation site selection. Genes Dev 30: $1558-1572$.

Loya TJ, Reines D. 2016. Recent advances in understanding transcription termination by RNA polymerase II. F1000Res 5: 1478.

Martens JA, Laprade L, Winston F. 2004. Intergenic transcription is required to repress the Saccharomyces cerevisiae SER3 gene. Nature 429: 571-574.

Martens JA, Wu PY, Winston F. 2005. Regulation of an intergenic transcript controls adjacent gene transcription in Saccharomyces cerevisiae. Genes Dev 19: 2695-2704.

Mata J. 2013. Genome-wide mapping of polyadenylation sites in fission yeast reveals widespread alternative polyadenylation. RNA Biol 10: 1407-1414.

Moreira-Ramos S, Rojas DA, Montes M, Urbina F, Miralles VJ, Maldonado E. 2015. Casein kinase 2 inhibits HomolD-directed transcription by Rrn7 in Schizosaccharomyces pombe. FEBS J 282: 491-503.

Nabavi S, Nazar RN. 2008. U3 snoRNA promoter reflects the RNA's function in ribosome biogenesis. Curr Genet 54: 175-184.

Rojas DA, Moreira-Ramos S, Zock-Emmenthal S, Urbina F, Contreras-Levicoy J, Käufer NF, Maldonado E. 2011. Rrn7 protein, an RNA polymerase I transcription factor, is required for RNA polymerase II-dependent transcription directed by core promoters with a HomolD box sequence. J Biol Chem 286: 26480-26486.

Schwer B, Shuman S. 2011. Deciphering the RNA polymerase II CTD code in fission yeast. Mol Cell 43: 311-318.

Schwer B, Sanchez AM, Shuman S. 2012. Punctuation and syntax of the RNA polymerase II CTD code in fission yeast. Proc Natl Acad Sci 109: 18024-18029.

Schwer B, Bitton DA, Sanchez AM, Bähler J, Shuman S. 2014. Individual letters of the RNA polymerase II CTD code govern distinct gene expression programs in fission yeast. Proc Natl Acad Sci 111: $4185-4190$.

Schwer B, Sanchez A, Shuman S. 2015. RNA polymerase II CTD phospho-sites Ser5 and Ser7 govern phosphate homeostasis in fission yeast. RNA 21: 1770-1780.

Schwer B, Sanchez AM, Garg A, Chatterjee D, Shuman S. 2017. Defining the DNA binding site recognized by the fission yeast $\mathrm{Zn}_{2} \mathrm{Cys}_{6}$ transcription factor $\mathrm{Pho} 7$ and its role in phosphate homeostasis. mBio 8: $\mathrm{e} 01218-17$.

Shah S, Wittmann S, Kilchert C, Vasiljeva L. 2014. lncRNA recruits RNAi and the exosome to dynamically regulate phol expression in response to phosphate levels in fission yeast. Genes Dev 28: 231-244. 
Sugiyama T, Sugioka-Sugiyama R. 2011. Red1 promotes the elimination of meiosis-specific mRNAs in vegetatively growing fission yeast. EMBO J. 30: 1027-1039.

Wang C, Zhu Y, Bao H, Jiang Y, Xu C, Wu J, Shi Y. 2016. A novel RNAbinding mode of the YTH domain reveals the mechanism for recognition of determinant of selective removal by Mmil. Nucleic Acids Res 44: 969-982.

Witt I, Straub N, Käufer NF, Gross T. 1993. The CAGTCACA box in the fission yeast Schizosaccharomyces pombe functions like a TATA element and binds a novel factor. EMBO J 12: 1201-1203.
Witt I, Kwart M, Gro $\beta$ T, Käufer NF. 1995. The tandem repeat AGGGTAGGGT is, in the fission yeast, a proximal activation sequence and activates basal transcription mediated by the sequence TGTGACTG. Nucleic Acids Res 23: 42964302 .

Yamashita A, Shichino Y, Tanaka H, Hiriart E, Touat-Todeschini L, Vavasseur A, Ding DQ, Hiraoka Y, Verdel A, Yamamoto M. 2012. Hexanucleotide motifs mediate recruitment of the RNA elimination machinery to silent meiotic genes. Open Biol 2: 120014. 

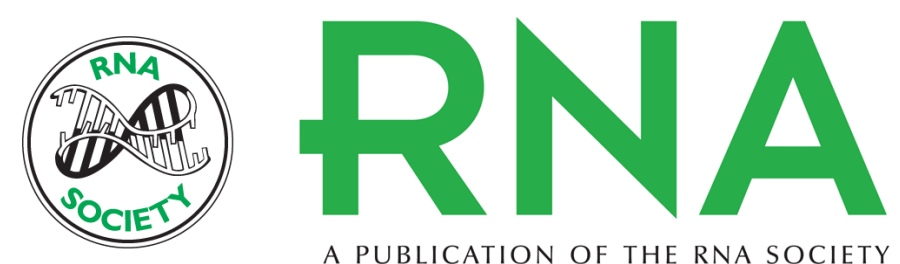

A PUBLICATION OF THE RNA SOCIETY

\section{Poly(A) site choice and Pol2 CTD Serine-5 status govern IncRNA control of phosphate-responsive tgp1 gene expression in fission yeast}

Ana M. Sanchez, Stewart Shuman and Beate Schwer

RNA 2018 24: 237-250 originally published online November 9, 2017 Access the most recent version at doi:10.1261/rna.063966.117

Supplemental Material

References

Creative Commons License

Email Alerting Service
http://rnajournal.cshlp.org/content/suppl/2017/11/09/rna.063966.117.DC1

This article cites 31 articles, 12 of which can be accessed free at: http://rnajournal.cshlp.org/content/24/2/237.full.html\#ref-list-1

This article is distributed exclusively by the RNA Society for the first 12 months after the full-issue publication date (see http://rnajournal.cshlp.org/site/misc/terms.xhtml). After 12 months, it is available under a Creative Commons License (Attribution-NonCommercial 4.0 International), as described at http://creativecommons.org/licenses/by-nc/4.0/.

Receive free email alerts when new articles cite this article - sign up in the box at the top right corner of the article or click here.

To subscribe to $R N A$ go to:

http://rnajournal.cshlp.org/subscriptions 